\title{
Corrosive sulfur associated with dibenzyl disulfide in fluid-filled transformers
}

\author{
Veresha Dukhi, Ajay Bissessur and Bice S. Martincigh* \\ School of Chemistry and Physics, University of KwaZulu-Natal, Westville Campus, Private \\ Bag X54001, Durban, 4000, South Africa
}

*Corresponding author: Tel: +27 31 2601394; Fax: +27 31 2603091;

E-mail: martinci@ukzn.ac.za 


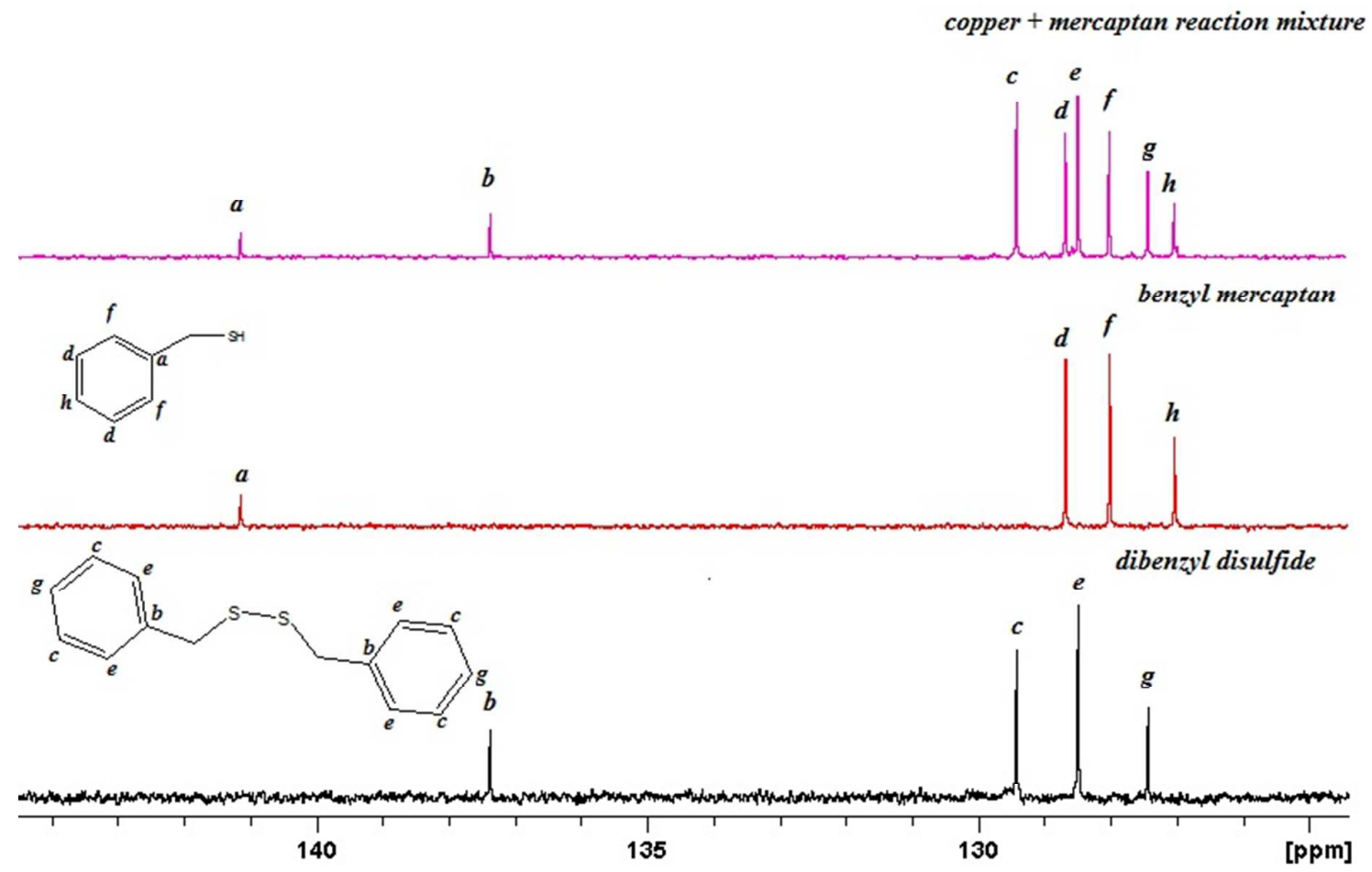

Figure S1. ${ }^{13} \mathrm{C}$ NMR spectra showing the presence of dibenzyl disulfide (side-product) with benzyl mercaptan (starting material) in the reaction between a copper plate and benzyl mercaptan (Section 3.3). 


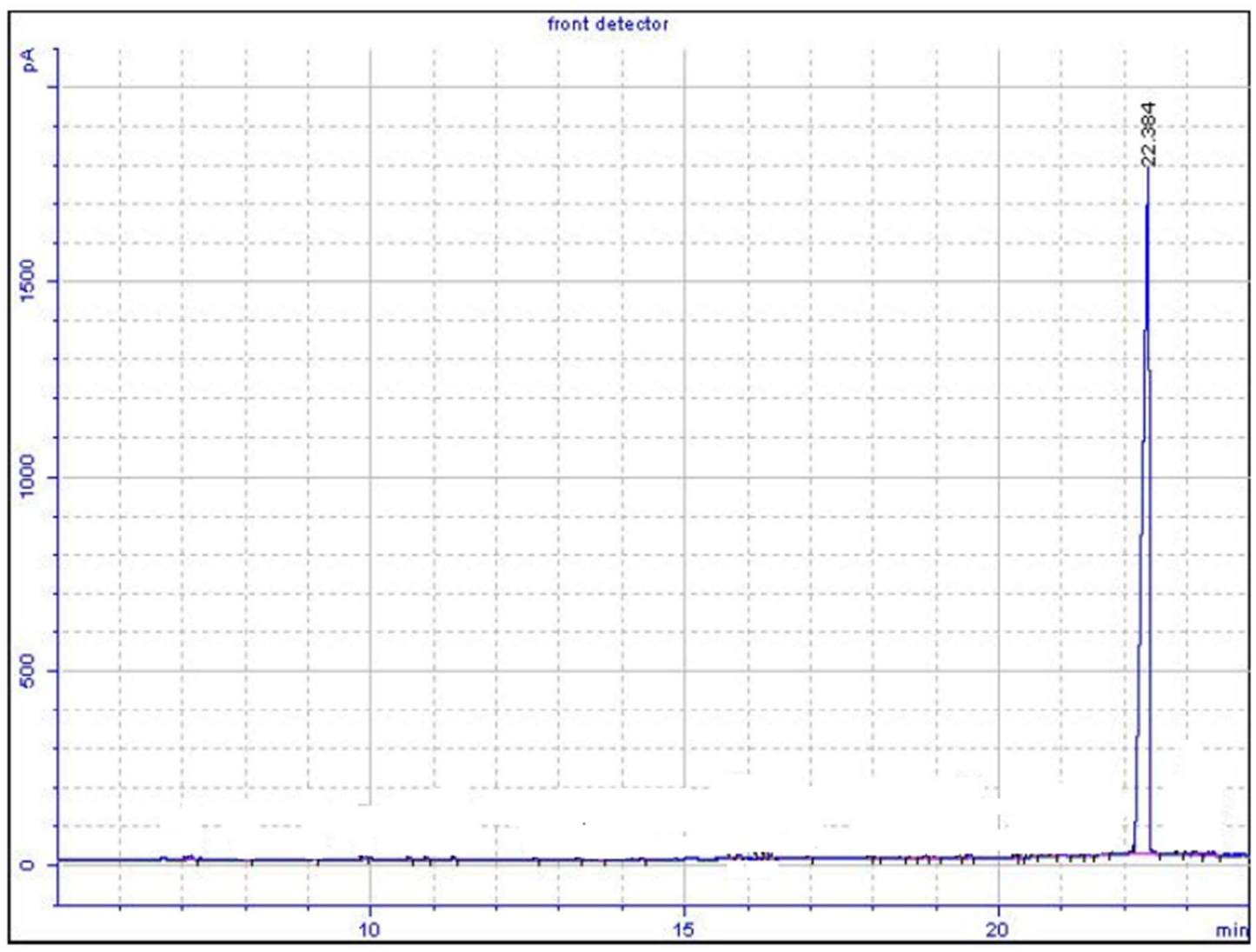

Figure S2. GC-FID chromatogram of the side-product formed by the reaction of benzyl mercaptan and copper oxide (Section 3.5). 


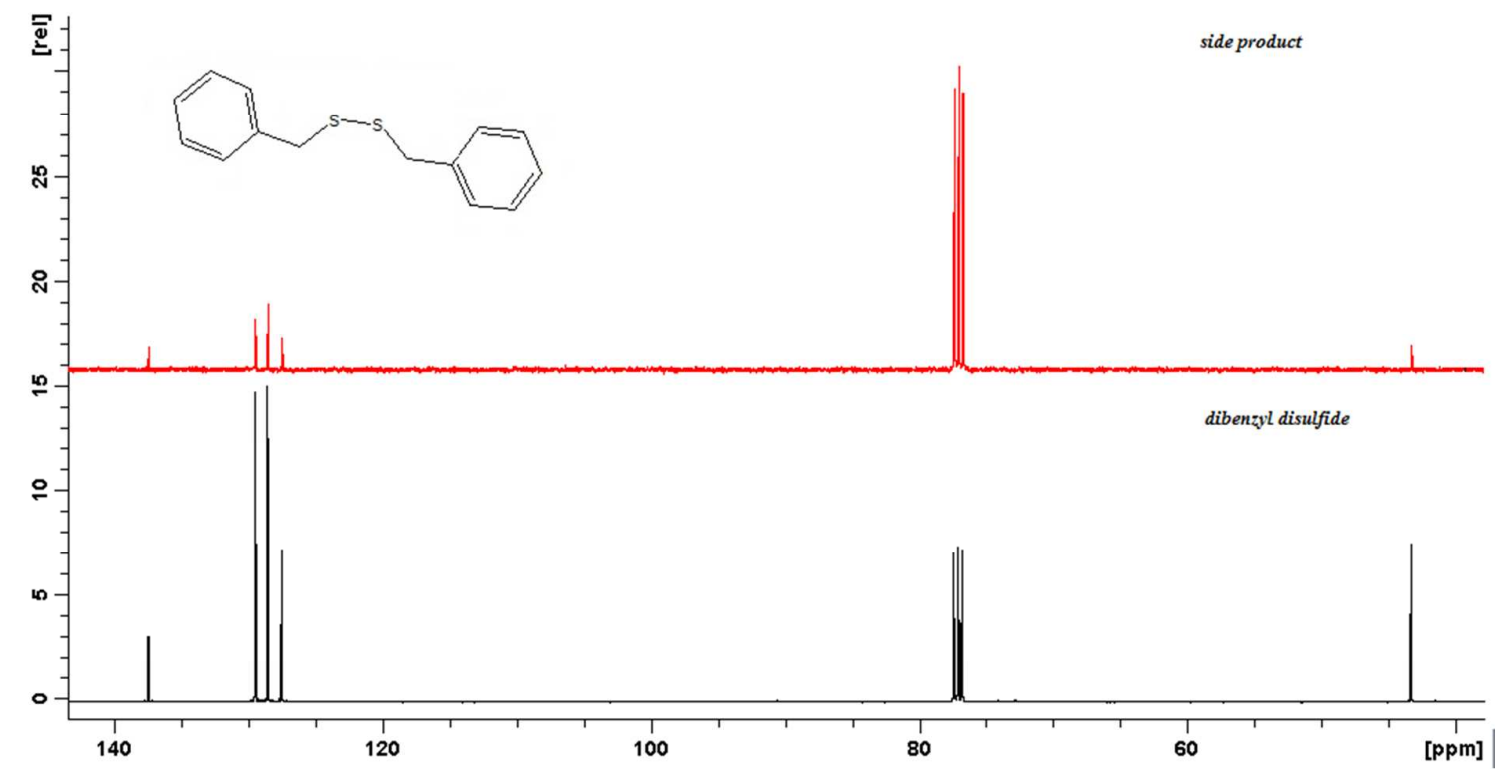

Figure S3. ${ }^{13} \mathrm{C}$ NMR spectra of the side-product formed by the reaction of benzyl mercaptan and copper oxide (Section 3.5).

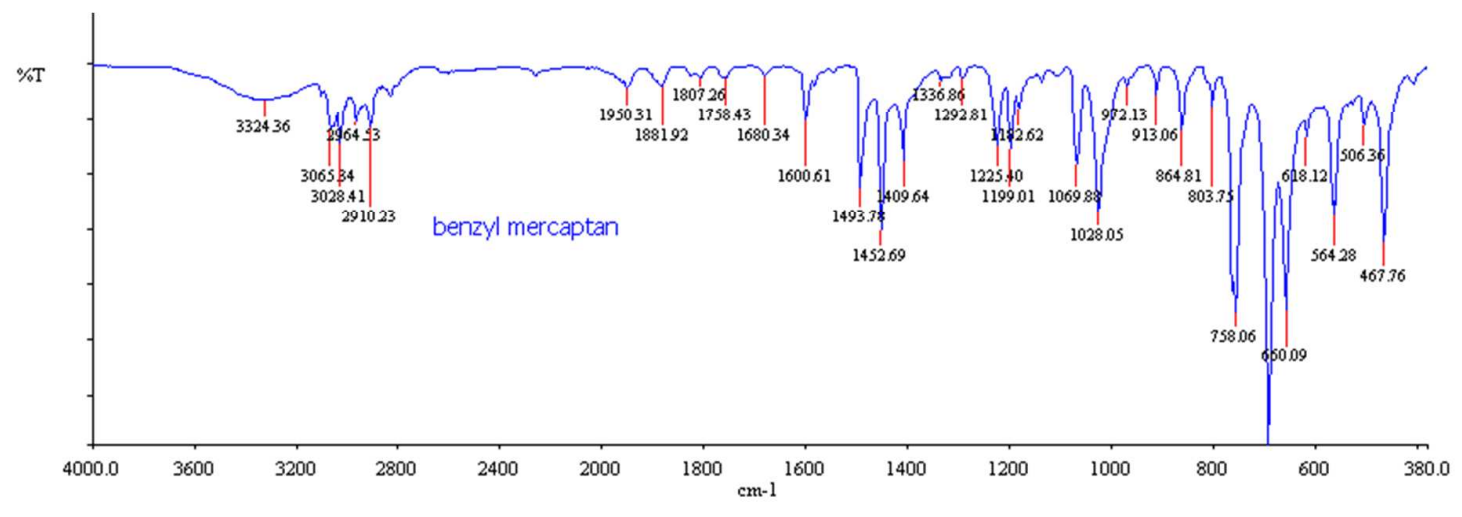

Figure S4. ATR-FTIR spectrum of benzyl mercaptan (Section 3.5). 


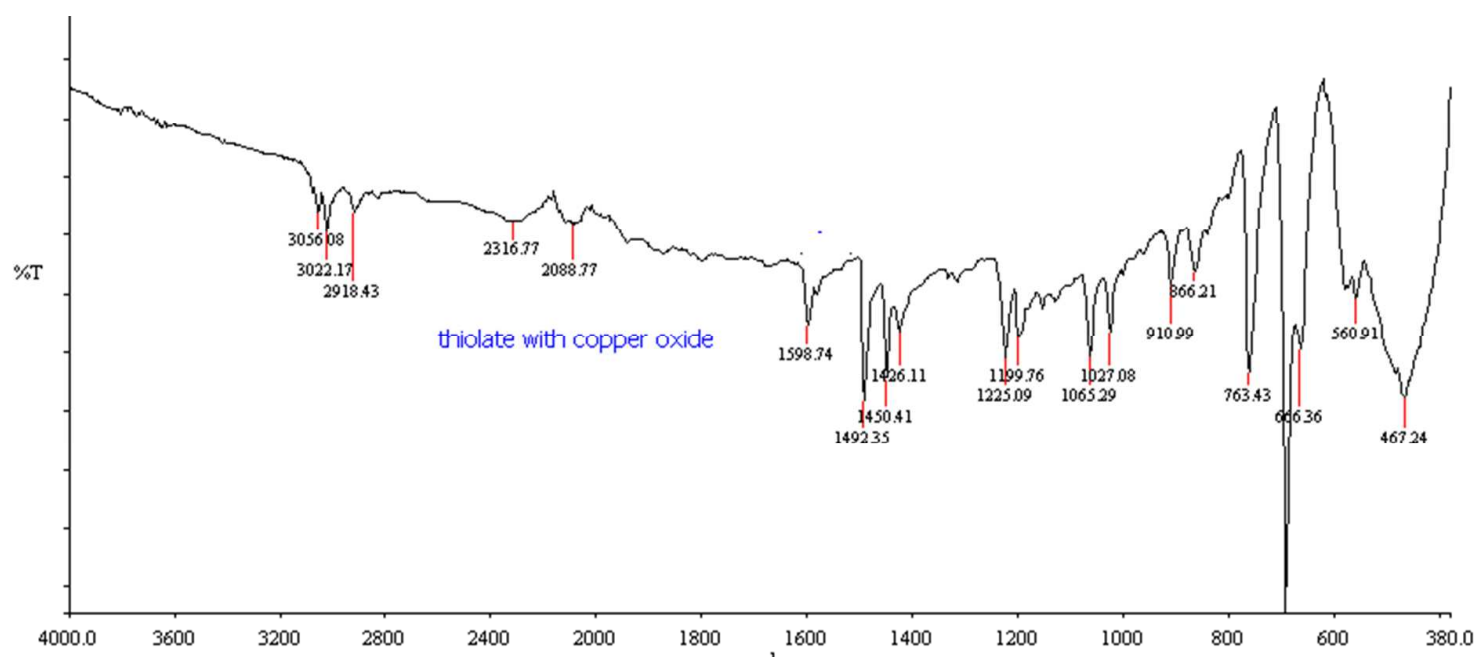

Figure S5. ATR-FTIR spectrum of copper thiolate (Section 3.5). 


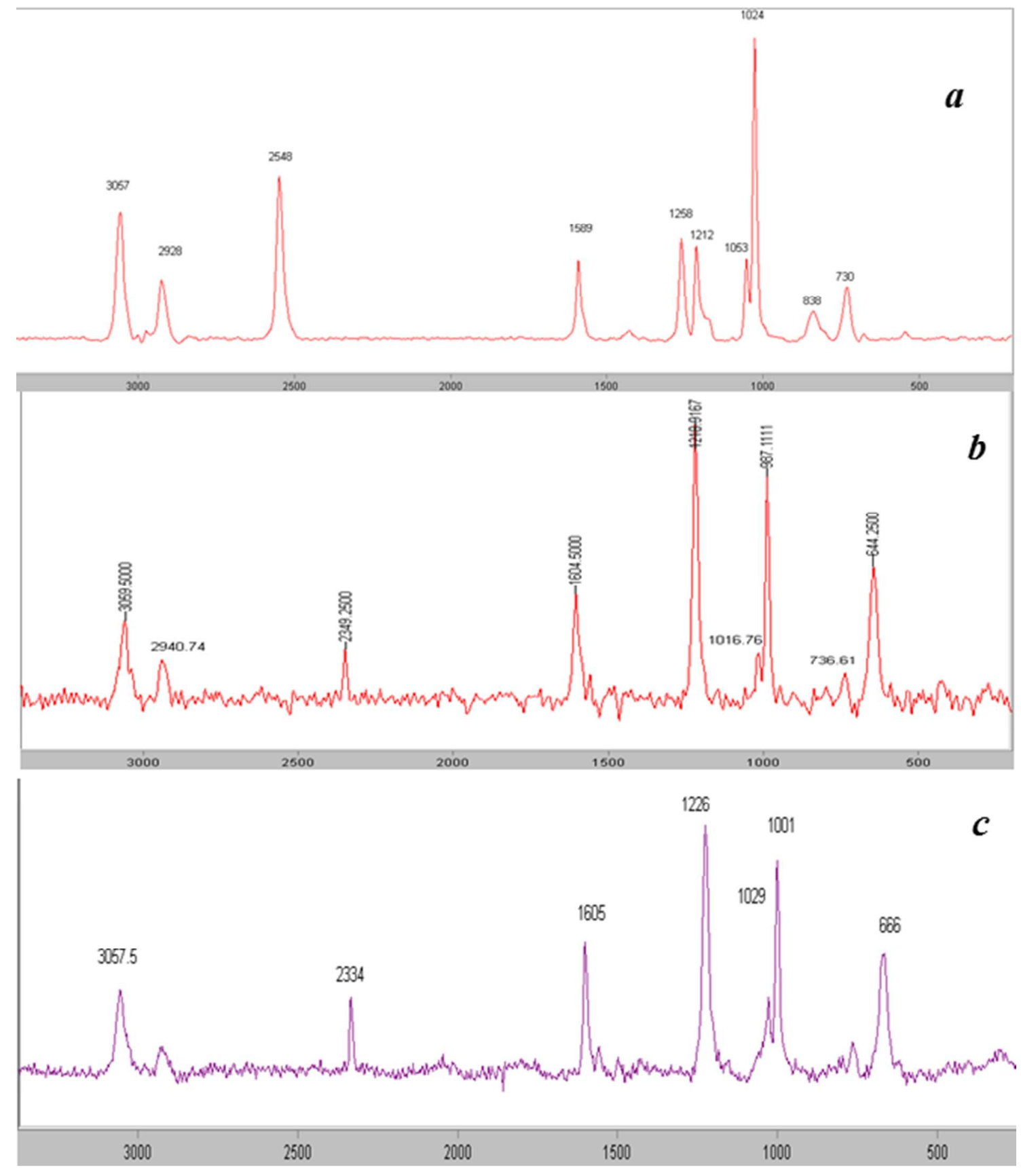

Figure S6. Raman spectra of ( $\boldsymbol{a}$ ) benzyl mercaptan, $(\boldsymbol{b}) \mathrm{Cu}$ thiolate (prepared by the $\mathrm{CuO}$ route) and (c) $\mathrm{Cu}$ thiolate (prepared by the deposition route) (Section 3.5). 


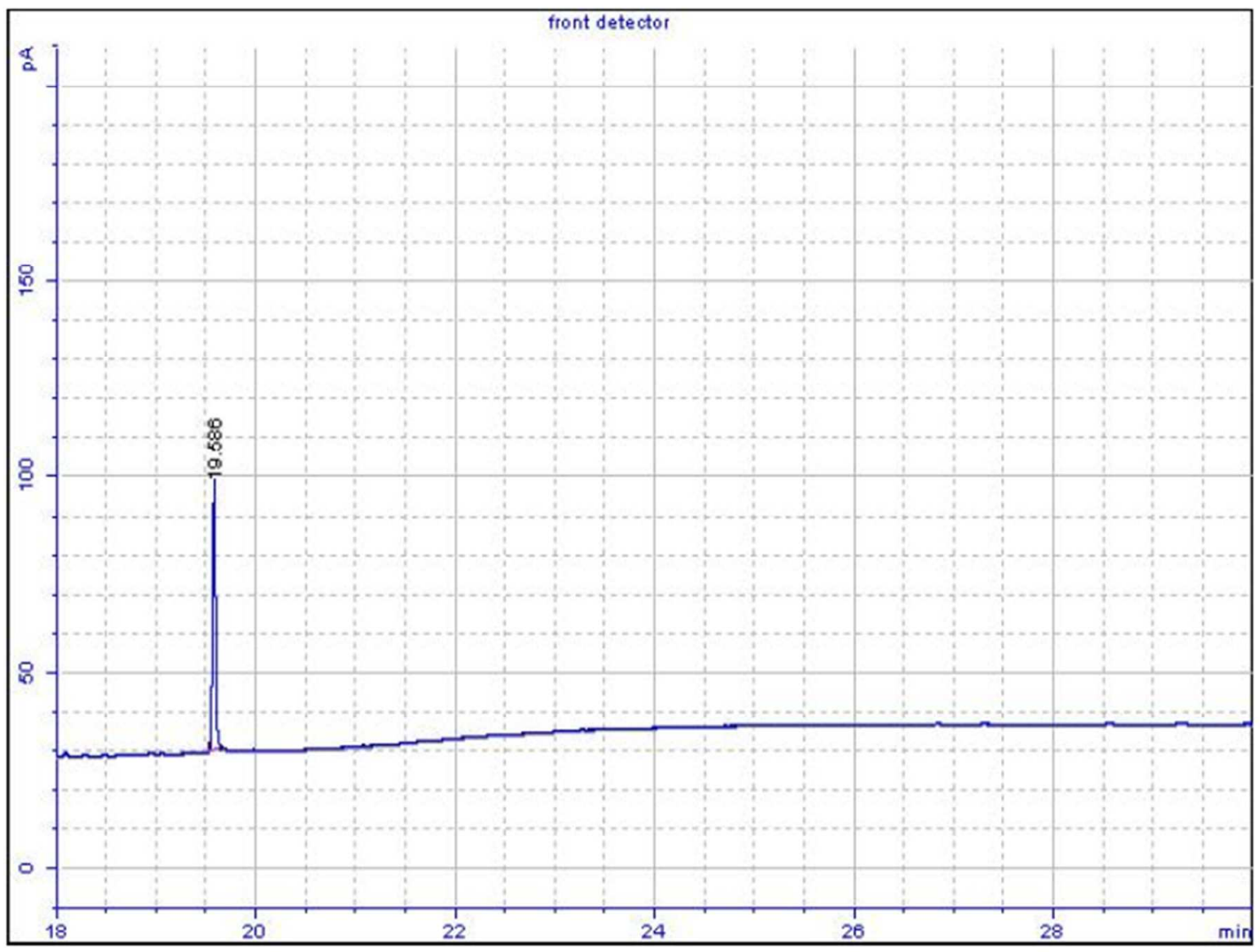

Figure S7. GC-FID chromatogram of the initial degradation product formed by thermolysis (Section 3.6). 


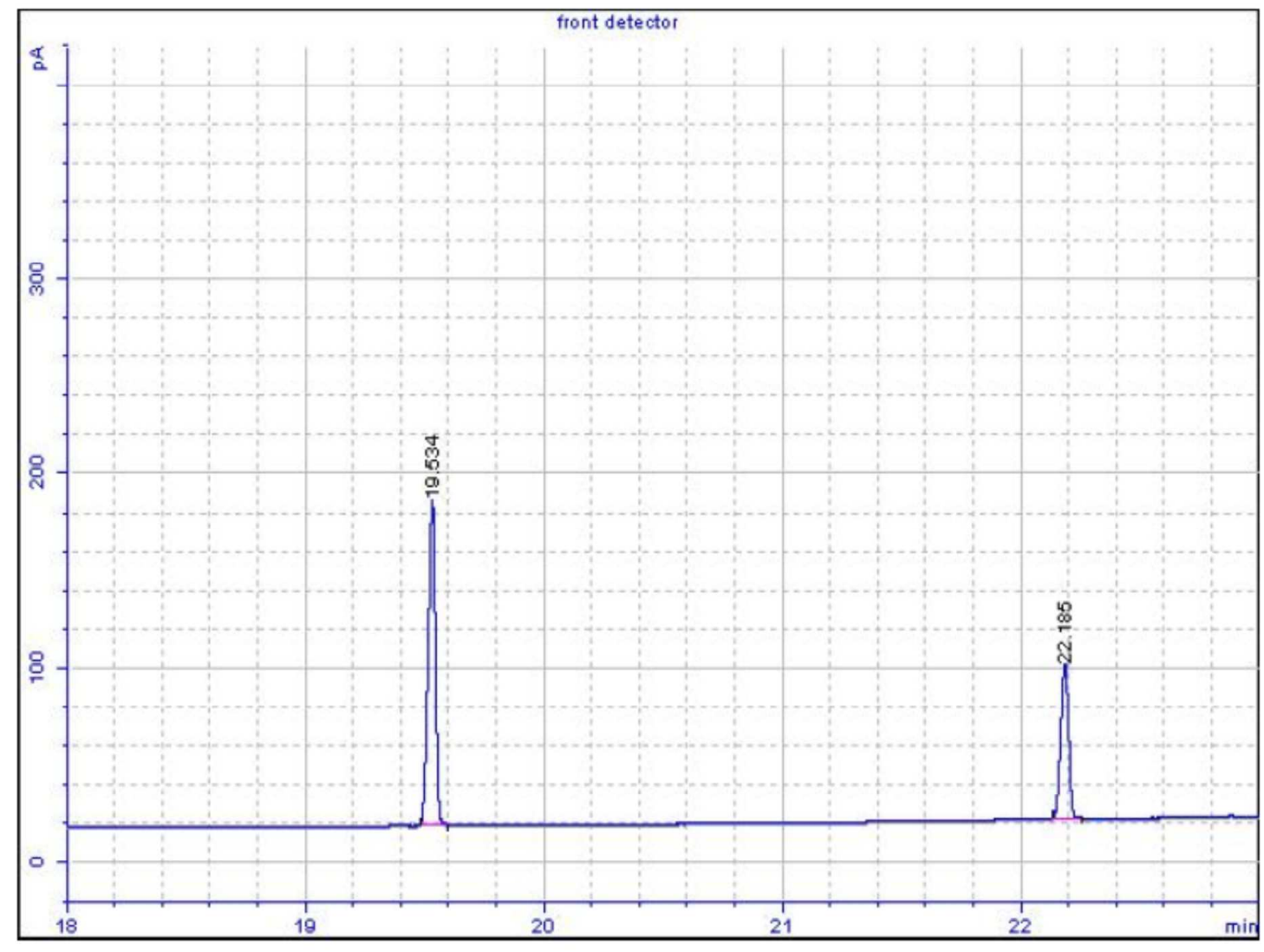

Figure S8. GC-FID chromatogram of the degradation products formed by thermolysis of the thiolate (Section 3.6). 